\title{
Education majors' expectations and reported experiences with inquiry-based physics: Implications for student affect
}

\author{
Jon D. H. Gaffney* \\ Department of Physics and Astronomy, Eastern Kentucky University, 521 Lancaster Avenue, Richmond, Kentucky 40475, USA
}

(Received 20 September 2012; published 5 April 2013)

\begin{abstract}
To address a perennial need to provide K-8 teachers with a solid foundation in science, there are many physics content courses throughout the United States. One such course is Physics and Astronomy for Teachers (PAT), which relies heavily on active-learning strategies. Although PAT is successful in teaching physics content, students sometimes report dissatisfaction with the course. Such instances of poor affect are worrisome because they may influence how teachers present science in their own classrooms. Therefore, this study investigates students' affect in terms of their pedagogical expectations and potential personal learning outcomes with respect to PAT. Two sections of PAT, each containing approximately 40 students, were observed. Students in those sections were surveyed, and a sample were interviewed $(N=10)$. An analysis of the data in terms of an expectancy violation framework shows that while students' expectations regarding the hands-on and interactive components of PAT were met, they received substantially fewer lectures, class discussions, and opportunities to make class presentations than they had expected, even after they had been presented with the course syllabus and informed about the specific nature of the course. Additionally, students expected PAT to be more directly linked with their future teaching careers and therefore expected more opportunities to practice teaching science than they reported receiving. This investigation serves as a case study to provide insight into why students are sometimes frustrated and confused when first encountering active-learning classes, and it implies that instructors should be cognizant of those feelings and devote resources toward explicit orientation that emphasizes the purpose of the course and reasons behind their pedagogical choices.
\end{abstract}

DOI: 10.1103/PhysRevSTPER.9.010112

PACS numbers: 01.40.Fk, 01.40.Di, 01.40.jc

\section{INTRODUCTION}

Education reform in the science, technology, engineering, and mathematics (STEM) disciplines has been a perennial need throughout the United States, called for by numerous publications [1,2] and legislation [3]. One major piece of that reform has been with respect to teacher preparation: future teachers need to develop a fundamental understanding of science, even when they plan on teaching at pre-high school levels [4]. Within the discipline of physics, students arrive in high school sorely underprepared [5], and we are therefore tasked with teaching elementary and middle education majors physics while using methods that dovetail with those that they will be expected to use in the K-8 classroom. Such methods, supported by publications such as How Students Learn [6], are based in constructivist philosophy and encourage students to be active investigators, exploring phenomena and seeking explanations through a variety of activities.

This challenge of preparing teachers, while enhanced of late by the pending publication of reformed science

\footnotetext{
*jon.gaffney@eku.edu

Published by the American Physical Society under the terms of the Creative Commons Attribution 3.0 License. Further distribution of this work must maintain attribution to the author(s) and the published article's title, journal citation, and DOI.
}

standards [7], has been addressed in past decades by multiple curriculum developers and resulted in highly effective curricula such as Physics by Inquiry [8] and Physics and Everyday Thinking [9]. Specifically within the state of Kentucky, motivated by earlier national science standards [2] and legislation such as the Kentucky Education Reform Act, faculty from both Education and Physics Departments at the University of Kentucky (UK), with help from faculty at neighboring institutions, developed Physics and Astronomy for Teachers (PAT), drawing largely from resources such as Physics by Inquiry and Workshop Physics [10]. PAT was later adopted at multiple regional universities through the Appalachian Math and Science Partnership [11].

PAT quickly became a required course for elementary, middle school, and special education majors at UK. Studies demonstrated that PAT was effective at improving understanding of physical science topics reflected in the standards, such as astronomy [12] and light [13]. However, despite these gains, PAT received mixed reviews from students, and numerous students displayed signs of animosity toward the course including intimidation by the subject, frustration from the difficulty of the course content, and confusion at the seeming irrelevance of PAT to their future careers, all of which may stem from their lack of familiarity with physical science. Moreover, the pedagogical activities that engaged students in PAT were fairly 
unique within the university; rarely in other classes were students expected to develop their own understanding of a concept and explain it to an instructor prior to that instructor first telling them precisely what they were expected to learn.

Poor student affect in physics courses is especially worrisome when those students will become teachers of elementary and middle school students. If elementary school teachers feel that physical science is not relevant, or if they have a distaste for it, they will likely avoid teaching it regardless of how well they understand it. As a science education instructor said during an interview in this study, "I can't think of anything more important for an elementary preservice teacher than to be excited about teaching science. If you're not excited about it, you won't teach it, and you'll avoid everything about it." In other words, it will do us very little good to improve science teachers' science content knowledge if we do not also foster their desire to teach science.

Therefore, we should strive to understand why some students dislike courses like PAT. Doing so should generate actionable implications for enhancing content courses for preservice teachers to make them more likely to impact K-8 students. While this study deals strictly with one such content course, the intention is that it can be used as a case study for other courses where, although students are learning physics, they are displaying frustration and otherwise not "buying in" to the value and purpose of the course. Specifically, the goal is that this study can point to ways that instructors can mitigate those feelings of frustration and confusion that preservice teachers sometimes develop, thereby improving their attitudes toward science and science teaching for when they begin teaching.

\section{BACKGROUND}

\section{A. Affective research in physics education research}

Preservice teachers are not the only population who have shown frustration with research-based instructional strategies. Indeed, throughout many different levels of physics instruction, successful implementation of those strategies continues to be a challenge. A third of the faculty members who reported trying a research-based instructional strategy in introductory physics courses abandoned that strategy [14]. One hypothesized reason for instructors dropping the strategy after one attempt was directly related to student affect; specifically, it is possible that instructors are dissuaded by complaints by students. Even within established programs, student complaints about pedagogically reformed classes are a major problem. The implementation of TEAL at MIT suffered low student evaluations [15], and student surveys of students in SCALE-UP revealed dissatisfaction because some students felt they could have earned the same grade with less work in a lecture class [16].

Within the physics education research community, much of the investigation into student attitudes and affect have their roots in epistemology, or the concept that students' beliefs and expectations about physics, knowledge, and learning affect their performance in the classroom and beyond. Indeed, studies have found that epistemology is an important factor in student learning $[17,18]$, and that explicit instruction about epistemology makes students more expertlike in their understandings about how physics is learned [19].

From epistemological roots have emerged studies about student attitudes, including the development of multiple surveys such as the Maryland Physics Expectations Survey (MPEX) [20], Epistemological Beliefs Assessment for Physical Science (EBAPS) [21], and most recently, Colorado Learning Attitudes about Science Survey (CLASS) [22]. Generally speaking, such surveys compare student epistemologies with experts; typical courses see a slight decline or no change in student scores, while some recent publications have demonstrated remarkable gains, usually by explicitly teaching epistemology $[23,24]$. Of note, one of those studies involved a physics content course for teachers using the Physics and Everyday Thinking curriculum [9]. Another study, which is particularly relevant considering it was done with the Physics by Inquiry curriculum at multiple institutions, found positive epistemological shifts in each implementation, although there was substantial variation between implementations [25]. The authors note that further work is yet required to isolate the features of Physics by Inquiry that led to success. These studies provide an interesting, but incomplete, background: on the one hand, students in PAT may have naive epistemologies which could lead to dissonance with active learning. On the other hand, one might expect that because PAT is largely based on the Physics by Inquiry curriculum, those epistemologies should shift to become more expertlike over the semester. It remains unclear how such epistemological stances should generate students' affect toward PAT.

The surveys listed above do not directly probe student perceptions about the course itself, nor is there an explicit link in the literature connecting student perceptions of their courses with epistemology. In fact, one study that measured both student satisfaction with an intervention and CLASS scores showed that although students were overwhelmingly dissatisfied with the intervention, which was a tutorial implementation, the class showed no gain or loss on the CLASS as a whole [26]. The authors liken the tutorials to a "potent medicine" which need not be pleasurable to be effective. Indeed, a hidden assumption about some instructional interventions may be that they are useful in improving cognitive gains, so they are worthwhile regardless of effects on student affect. However, if we are interested in influencing the behavior of future teachers, we ought to also attend to students' affect regarding the intervention or method of instruction. 


\section{B. Expectancy violation}

One useful lens for understanding how student affect in a course like PAT develops is expectancy violation (EV) [27,28], which is a framework from communication research that builds upon the assumption that people have certain expectations whenever they enter a given situation. When someone experiences behavior that falls outside the range of what they had expected, we call that a violation [29]. This violation may be interpreted negatively, resulting in discomfort and dissatisfaction, or it may be perceived positively, resulting in that person feeling especially pleased. The notion of framing [30] within physics education research overlaps somewhat, as framing carries similar assumptions and implies that what students expect from a certain situation can influence how they behave. Thus, there may be fruitful connections between $\mathrm{EV}$ and framing research in terms of how expectations and violations shape students' epistemologies, which then manifest as behaviors and attitudes. Even without fleshing out such theoretical underpinnings, EV can be used in a purely phenomenological sense to understand the relationship between violations and affect within an environment such as a science classroom.

The EV framework has been used to examine communication in classrooms. We know, for example, that students and instructors enter the classroom with different sets of expectations [31], and that those expectations can impact behaviors and perceptions in the classroom [32]. When students experience negative EV, it can result in negative evaluations of the course; for example, one study found that as the instructor violated expectations (for example, by showing anger in the classroom), students were more dissatisfied with the instructor and class [33].

Within the field of business and hospitality, a similar framework has yielded similar results. The "expectancydisconfirmation paradigm" presents customer satisfaction in terms of that customer's expectations [34]. When a customer experiences performance inferior to expectations, the customer is dissatisfied (and often complains); when the customer experiences superior performance, that customer reports satisfaction. This paradigm has been repeatedly tested and used as the basis for multiple studies on consumer behavior [35], and it has also been applied to the classroom. In such applications, students take on the role as customers, and the course is the service provided. When students' retroactively reported expectations about the course are not met, they report dissatisfaction on the end-of-semester evaluations [36]. A different study using this paradigm highlighted the influence of individual classroom incidents on student satisfaction [37]. They add that instructors should be able to increase students' satisfaction not by merely placating the students, but rather by convincing them of how the class structure supports learning and articulating their role in that setting.
Violating expectations is not inherently a bad thing. Indeed, doing so may provide an opportunity for students to change their epistemologies about physics and learning. However, such opportunities should be scaffolded to minimize dissatisfaction. One way to do this is to shift their expectations about how they should be taught; for example, as students become convinced that lecture is not always the best way for them to learn, they may feel that lecture is inappropriate behavior in certain situations and therefore expect it less. A previous study of students' expectations in a pedagogically reformed course showed that pedagogical expectations can be shifted very early in the semester when class time and instructor effort are explicitly devoted toward orienting the class [38].

Therefore, EV serves as a powerful framework for uncovering potential reasons for students' dissatisfaction in PAT, which in turn should suggest ways to improve orientation to the course so as to mitigate frustration and confusion.

\section{Research questions}

This investigation regarding student affect in PAT revolved around two major questions.

(1) How did the frequency of the pedagogical activities engaged within PAT meet or violate students' expectations? Specifically, what were students' initial expectations about the frequencies of different activities, what were students' perceptions of the actual experienced frequencies of those activities, and what was the effect of orientation to the course in terms of shifting expectations?

(2) What value did students attribute to potential outcomes in PAT? Additionally, how do their values for those outcomes at the end of the course compare to those at the beginning, how well did students feel that PAT met those potential outcomes, and how did those students' values compare with those of the instructors and those of science education instructors?

\section{STUDY DESIGN}

\section{A. Environment}

The fall 2010 implementation of PAT was a three-credit course that met for six hours each week in a laboratory room with ample table work space, poor acoustics, and little chalkboard space. Each of the two sections was filled to capacity with 44 students, most of whom (over 80\%) were female.

Within PAT, students were assigned into groups ranging from three to five students in size. Students performed guided inquiry activities during most of the class time. Many of these activities were selected from Physics by Inquiry [8], some were based on Workshop Physics [10] activities, and others were adaptations of UK's own Online 
Physics for Teachers [39], which is a collection of online physical science content courses for in-service teachers. Each instructor had the freedom to choose and modify activities for his [40] course. For the two sections observed in the fall of 2010, the instructor of section 1 chose mostly activities from Online Physics for Teachers, whereas the instructor of section 2 chose mainly Physics by Inquiry activities. Both sections covered similar content: electric circuits, magnetism, forces and motion, light and optics, and astronomy. The major content difference was that the instructor for section 1 also introduced heat at the expense of some magnetism instruction.

Each course had one lead instructor and one teaching assistant (TA). Additionally, I served as an assistant instructor without grading responsibility in both sections, so there were three instructors in each class. While students followed instructions from worksheets or the Physics by Inquiry textbook, the instructors answered student questions and performed "checks" with each small group of students. Each group was checked about once per hour. At these checks, students shared their progress and asked questions, and the instructors clarified the material and conducted Socratic-style discussions with the students.

Because of the design of the course, and reinforced by the classroom space, minimal lecture occurred during class. However, instructors occasionally addressed the entire class to review content, discuss practical matters, and introduce activities. Students were individually assessed via graded homework, quizzes, and exams.

Instructors introduced the students to the course by leading them through the syllabus and stressing that PAT would be different than other science courses they had taken. Students were briefed on how they would be learning within the class, and they began work on some activities for the first unit. This introduction will be referred to throughout this paper as the students' "orientation" to the course.

\section{B. Implementation}

Surveys were given to both sections of students at the beginning and at the end of the semester. Each survey consisted of two parts. The first part was an adaptation of the Pedagogical Expectancy Violation Assessment (PEVA) [38], on which students indicated how often they expected to experience each of 15 items detailing class-time activities such as "lecture," "to present and explain my work to the class," or "to answer questions from my classmate during class time." On the survey at the start of the semester, students indicated how frequently they expected such an event would occur on a 7-point Likert scale at two different times: when they first signed up for the course and after orientation to the course. On the survey at the end of the semester, students reported their experiences in the course. PEVA survey items are located in Appendix B.
In the second part of each survey, students used a 7-point Likert scale to rate the importance they attributed to each of 12 items that indicated different possible outcomes they could receive from the course such as "to learn science content knowledge" and "to become excited about science." At the end of the semester, students rated the same items and were also asked to report how well they felt they accomplished each item. This "outcomes" survey was developed through multiple discussions about course goals with several physics instructors who taught similar courses nationwide. These survey items can be found in Appendix C.

Each of the students enrolled in PAT in the fall of 2010 was given the opportunity to participate in this study. Students responded at a fairly high rate at both the begin$\operatorname{ning}(N=67$ responses out of a population of 92 students) and end $(N=76$ out of 88$)$ of the semester. In section 1 , the first survey was given online and received a particularly low response rate $(N=19$ out of 44$)$, but the later survey for that section was given during class and received more responses $(N=36$ out of 44$)$. Both surveys for section 2 were given during class and received high response rates ( $N=48$ out of 48 , pre; $N=40$ out of 44 , post).

To validate the students' responses to the surveys, students and instructors were both interviewed. A few students participated in an interview at the beginning $(N=3)$, with more participating at the end $(N=8)$ of the semester. One student chose to participate at both opportunities. During the interviews, students were asked about their goals, what they expected to do and learn, and (in the later interview) about their experiences in PAT. Additionally, the students were asked to reflect on some of the items from the survey to give further insight about their interpretation of terms like "lecture." The instructors who were interviewed included the two lead instructors during that semester, a former instructor who had a long history of developing and teaching the course, and two science education professors who taught the science methods course for preservice elementary and middle school teachers in the College of Education. Each of those participants was asked about his or her vision, expectations, and goals for the course and asked to discuss how they would respond to items on the "possible outcomes" survey.

I also observed the course as an ancillary instructor to complete the triangulation of the data. These observations allowed me to both observe the affect of the students in real time as well as provide instances to which I could refer during interviews, which helped provide a clearer picture of the survey results; see Sec. V.

\section{Data analysis}

Because of my role with the course, I asked students to not reveal their identities on surveys. This anonymity came with the trade-off that I could not pair data from the two surveys and could only analyze it in the aggregate. 
The data collected by the surveys were assumed to be ordinal and not normally distributed. Therefore, following the precedent in previous work [38], a Mann-Whitney U-test [41], rather than a t-test, was used to check for differences between distributions. When distributions were different, Cliff's delta $(\delta)$ was calculated to determine something akin to the effect size of the difference. $\delta$ ranges from -1 to +1 ; to achieve a score of -1 , each entry in the second data set is smaller than every entry in the first data set [42]. More detail about $\delta$ is provided in Appendix A.

When analyzing the PEVA, it was necessary to compare how often each pedagogical activity was "expected when enrolling," "expected after orientation to the course," and "experienced." Significant differences between distributions in students' initially reported expectations and ultimate experiences would indicate that an expectancy violation occurred. The size of this violation was determined by the magnitude of $\delta$, and the sign of $\delta$ indicated the direction of the violation. Sometimes there was evidence of expectancy violation, but students' expectations after orientation to the course were not significantly different from their reported experiences. In such instances, the orientation successfully brought students' expectations for the course in line with their eventual experiences. On the other hand, when a significant difference persisted or became more pronounced, that is evidence that the orientation failed to change the students' expectations appropriately towards their eventual experiences.

Analysis of students' responses to the outcomes portion of the survey were done by inspection, using the full frequency distributions as the primary indications for students' priorities for the listed possible outcomes, as well as their perceptions of how well those outcomes were achieved. The Mann-Whitney U-test was also used to compare students' responses to different items.

Because mean and standard error implicitly assume interval data (that is, they assume that the step size between each response is equal), they are not the best measure for reporting central tendency. On the other hand, the median provides a more appropriate measure of central tendency at the expense of detail about the distribution itself. Therefore, acknowledging the limitations of each measure, mean, standard error, and median are reported for students' responses to items on the surveys for illustration purposes.

The survey questions were validated during interviews by asking both instructors and students how they interpreted items on the surveys. Both instructors and students provided clarifications for the items, and those clarifications generally overlapped. For example, there was consistency on how the term "lecture" was interpreted; students spoke about lecture in terms of the instructor addressing the class and providing guidance for the activities, as well as explaining physical concepts. On the other hand, disagreement arose among the students and instructors about what was meant by the phrase, "to solve difficult problems"; for that reason, it is unclear how students interpreted that item and what their responses to that item mean. Because only individual items are interpreted here, such discrepancies mean only that individual items resulting in possible confusion need to be ignored in the analysis.

The responses to the surveys were validated with observations in the classrooms. For example, one striking difference between the sections was that section 2 required the students to keep their own notebooks, while students in section 1 received papers (worksheets) each day to fill out. Accordingly, students in section 1 reported that they "wrote in their own journal" almost never (median $=1)$, while students in section 2 (median $=7$ ) did so all the time. A similar but less dramatic effect was demonstrated with lecture: the instructor in section 1 began each class with a 15-20 minute review, while the instructor in section 2 did not. Students reported substantially more lecture in section $1($ median $=4.5)$ than in section 2 $($ median $=2)$.

Additionally, students were given the opportunity to list alternative desired goals or outcomes in the course both during interviews and on the surveys themselves. These additional goals were largely about learning how to teach or explain the concepts and getting a good grade. Learning how to teach scientific concepts was not a goal of the course, according to the instructors, and that dissonance will be discussed at greater length in Sec. V.

Internal reliability, measured with Cronbach's alpha, was at acceptable levels for each set of questions $(0.78$, 0.72 , and 0.80 for the PEVA; 0.86, 0.92, and 0.95 for the "outcomes" portions of the survey).

\section{RESULTS}

\section{A. Expectancy violation}

Students' reported expectations and experiences are presented in Tables I and II. Because students in the two sections reported different experiences (and that difference was verified by observation), each section of the course was analyzed separately. Identifying the differences between the sections was not a goal for this research project, so details about their differences are not elaborated here.

Multiple instances of expectancy violation were indicated from the data. For each instance, $\delta$ is displayed in Table III. A negative value for $\delta$ indicates that students report the activity occurring less frequently than students expected; a positive value indicates that the activity occurred more than they expected.

Students also reported how the orientation to the course shifted their expectations about what was to happen during the course. These shifted expectations were compared to the students' experiences at the end of the semester to determine whether the orientation to the course was successful at bridging that gap between 
TABLE I. Students in section 1 reported how often they expected certain pedagogical activities in PAT when they initially enrolled and again after orientation. They also reported how frequently they ultimately experienced those activities at the end of the semester. A rating of seven means "very frequently." Results are formatted as mean (standard error); median.

\begin{tabular}{|c|c|c|c|}
\hline Activity within PAT & $\begin{array}{l}\text { Expected frequency } \\
\text { when enrolling }\end{array}$ & $\begin{array}{l}\text { Expected frequency } \\
\text { after orientation }\end{array}$ & Experiences \\
\hline Lecture & $5.6(0.32) ; 6$ & $4.8(0.47) ; 5$ & $4.2(0.32) ; 4.5$ \\
\hline Solving problems on my own during class & $5.3(0.23) ; 6$ & $5.8(0.29) ; 6$ & $5.6(0.25) ; 6$ \\
\hline Solving problems in a group during class & $5.7(0.24) ; 6$ & $6.4(0.20) ; 7$ & $6.8(0.083) ; 7$ \\
\hline Investigating how things work during class & $5.8(0.26) ; 6$ & $6.3(0.19) ; 6$ & $6.7(0.11) ; 7$ \\
\hline Class-wide discussions of scientific concepts & $5.3(0.27) ; 5$ & $5.3(0.21) ; 5.5$ & $4.3(0.27) ; 4$ \\
\hline Class-wide discussions of ways to teach science & $5.4(0.28) ; 6$ & $5.0(0.32) ; 5$ & $3.1(0.32) ; 3$ \\
\hline Class-wide discussions of the nature of science & $4.9(0.30) ; 5$ & $5.3(0.23) ; 5$ & $3.8(0.32) ; 4$ \\
\hline Answering questions from my instructors or TAs during class time & $5.1(0.34) ; 5$ & $5.6(0.20) ; 6$ & $5.6(0.26) ; 6$ \\
\hline Answering questions from my classmates during class time & $4.6(0.34) ; 5$ & $5.1(0.21) ; 5$ & $5.0(0.25) ; 5$ \\
\hline Asking questions about science of instructors or TAs during class time & $5.4(0.23) ; 5$ & $5.6(0.24) ; 6$ & $5.4(0.21) ; 5.5$ \\
\hline Asking questions about science of my classmates during class time & $4.8(0.26) ; 4$ & $5.6(0.23) ; 6$ & $5.1(0.26) ; 5.5$ \\
\hline Presenting and explaining my work to the class & $3.9(0.36) ; 4$ & $4.3(0.38) ; 4$ & $2.6(0.32) ; 2$ \\
\hline Writing in my own journal detailing class events & $3.5(0.37) ; 3$ & $4.1(0.43) ; 4.5$ & $2.9(0.42) ; 1$ \\
\hline Building my own understanding of concepts & $5.5(0.30) ; 6$ & $5.9(0.21) ; 6$ & $5.4(0.22) ; 6$ \\
\hline Receiving detailed instructions for doing scientific investigations & $5.7(0.29) ; 6$ & $5.6(0.38) ; 6$ & $5.6(0.22) ; 6$ \\
\hline
\end{tabular}

the students' initial expectations about the course and what they reported experiencing. Expectations for the frequency of a few activities were successfully shifted in one or more sections of PAT; these activities are noted in Table III with asterisks. However, even after orientation, students still held expectations that were substantially different from their ultimate experiences for some activities, including class-wide discussions and presenting their work to the class. In those activities, the introduction to the course was insufficient to change the students' expectations for PAT.

\section{B. Student outcomes}

The students were asked to reflect on 12 outcomes they could potentially achieve from taking PAT and rate how important they thought those outcomes were to them personally, at both the start and the end of the semester. Both sections of students responded similarly; there was no significant difference between the two sections at either the beginning or end of the semester. This finding supports the assumption that students distributed themselves fairly randomly between the two sections, and the data were therefore combined for analysis.

TABLE II. Students in section 2 reported how often they expected certain pedagogical activities when they initially enrolled in PAT and again after orientation. They also reported how frequently they ultimately experienced those activities at the end of the semester. A rating of seven means "very frequently." Results are formatted as mean (standard error); median.

\begin{tabular}{|c|c|c|c|}
\hline Activity within PAT & $\begin{array}{l}\text { Expected frequency } \\
\text { when enrolling }\end{array}$ & $\begin{array}{l}\text { Expected frequency } \\
\text { after orientation }\end{array}$ & Experiences \\
\hline Lecture & $4.8(0.20) ; 5$ & $3.8(0.27) ; 4$ & $2.2(0.23) ; 2$ \\
\hline Solving problems on my own during class & $5.5(0.16) ; 6$ & $5.1(0.24) ; 5.5$ & $5.5(0.28) ; 6$ \\
\hline Solving problems in a group during class & $6.2(0.12) ; 6$ & $6.5(0.10) ; 7$ & $6.6(0.11) ; 7$ \\
\hline Investigating how things work during class & $6.4(0.12) ; 7$ & $6.3(0.13) ; 7$ & $6.4(0.17) ; 7$ \\
\hline Class-wide discussions of scientific concepts & $4.8(0.20) ; 5$ & $5.0(0.17) ; 5$ & $2.6(0.23) ; 2$ \\
\hline Class-wide discussions of ways to teach science & $5.1(0.17) ; 5$ & $5.2(0.16) ; 5$ & $2.2(0.21) ; 2$ \\
\hline Class-wide discussions of the nature of science & 4.9 (0.19); 5 & $4.9(0.18) ; 5$ & $2.5(0.24) ; 2$ \\
\hline Answering questions from my instructors or TAs during class time & $4.8(0.19) ; 5$ & $4.7(0.16) ; 5$ & $5.7(0.22) ; 6$ \\
\hline Answering questions from my classmates during class time & $4.5(0.21) ; 5$ & $4.9(0.18) ; 5$ & $5.0(0.23) ; 5$ \\
\hline Asking questions about science of instructors or TAs during class time & $5.2(0.16) ; 5$ & $5.3(0.19) ; 5.5$ & $4.8(0.23) ; 5$ \\
\hline Asking questions about science of my classmates during class time & $4.5(0.21) ; 4.5$ & $4.7(0.22) ; 5$ & $4.7(0.25) ; 5$ \\
\hline Presenting and explaining my work to the class & $3.3(0.20) ; 3.5$ & $3.7(0.22) ; 4$ & $1.6(0.18) ; 1$ \\
\hline Writing in my own journal detailing class events & $4.5(0.24) ; 5$ & $5.5(0.24) ; 6$ & $6.0(0.27) ; 7$ \\
\hline Building my own understanding of concepts & $5.8(0.15) ; 6$ & $6.1(0.12) ; 6$ & $5.4(0.26) ; 6$ \\
\hline Receiving detailed instructions for doing scientific investigations & $6.2(0.15) ; 6$ & $6.1(0.13) ; 6$ & $4.5(0.31) ; 5$ \\
\hline
\end{tabular}


TABLE III. Cliff's delta ( $\delta$, ranging from -1 to +1 , denoting effect size) for expectancy violations in PAT (n.s. indicates no significant difference between expectations and experiences). A negative value for $\delta$ indicates that the item was experienced less than expected. An asterisk denotes that although expectancy violation was present for those items, the orientation to the class shifted students' expectations such that there was no difference between their expectations after orientation and their reported experiences in the course for those items.

\begin{tabular}{|c|c|c|}
\hline \multirow[b]{2}{*}{ Aspect of PAT } & \multicolumn{2}{|c|}{ Size of expectancy violation } \\
\hline & Section 1 & Section 2 \\
\hline Lecture & $-0.42^{*}$ & -0.79 \\
\hline Solving problems on my own during class & n.s. & n.s. \\
\hline Solving problems in a group during class & $0.58^{*}$ & $0.31^{*}$ \\
\hline Investigating how things work during class & $0.51^{*}$ & n.s. \\
\hline Class-wide discussions of scientific concepts & -0.33 & -0.78 \\
\hline Class-wide discussions of ways to teach science & -0.64 & -0.86 \\
\hline Class-wide discussions of the nature of science & -0.35 & -0.76 \\
\hline Answering questions from my instructors or TAs during class time & n.s. & 0.41 \\
\hline Answering questions from my classmates during class time & n.s. & n.s. \\
\hline Asking questions about science of instructors or TAs during class time & n.s. & n.s. \\
\hline Asking questions about science of my classmates during class time & n.s. & n.s. \\
\hline Presenting and explaining my work to the class & -0.48 & -0.68 \\
\hline Writing in my own journal detailing class events & -0.30 & $0.58^{*}$ \\
\hline Building my own understanding of concepts & n.s. & n.s. \\
\hline Receiving detailed instructions for doing scientific investigations & n.s. & -0.54 \\
\hline
\end{tabular}

The overall distribution of responses did not change over the course of the semester, except with respect to the items, "To appreciate the benefits of a hands-on, interactive approach to teaching science," "To learn how to solve difficult problems," and "To gain an appreciation of scientific views of the world." The students rated each of those items as less important at the end of the semester compared to the start of the semester $(p<0.05)$. A more detailed analysis reveals that the shifts only occurred in section 2 , with $\delta$ values of $-0.34,-0.36$, and -0.26 , respectively. There was apparently a relatively small but significant shift in the value students placed on achieving these particular outcomes, although as mentioned previously, it is unclear how students interpreted the phrase "difficult problems." Nonetheless, these results suggest that students' goals in PAT remained generally static over the course of the semester, although experiences in the course have the potential to shift them slightly, as they

TABLE IV. Students reported how important they thought it would be to achieve certain possible outcomes in PAT [a rating of 7 means "very important (crucial)"]. They also reported how well they achieved those particular outcomes in PAT, split by section (a rating of 7 means "very successful"). Results are formatted as mean (standard error); median. Outcomes noted with an asterisk denote a significant difference $(p<0.05)$ between sections in terms of students' reported achievement of that outcome.

\begin{tabular}{|c|c|c|c|}
\hline \multirow[b]{2}{*}{ Possible outcome for PAT } & \multirow{2}{*}{$\begin{array}{l}\text { Importance } \\
\text { Combined }\end{array}$} & \multicolumn{2}{|c|}{$\begin{array}{l}\text { Students' reported degree } \\
\text { of achieving outcome }\end{array}$} \\
\hline & & Section 1 & Section 2 \\
\hline To learn science content knowledge (e.g., to learn about electricity) & $5.7(0.13) ; 6$ & $5.1(0.25) ; 5$ & $4.6(0.26) ; 5$ \\
\hline To learn how to argue scientifically* & $4.8(0.16) ; 5$ & $4.9(0.22) ; 5$ & $3.8(0.25) ; 4$ \\
\hline $\begin{array}{l}\text { To appreciate the benefits of a hands-on, interactive approach } \\
\text { to teaching science* }\end{array}$ & $6.0(0.14) ; 6$ & $5.9(0.17) ; 6$ & $4.8(0.32) ; 5$ \\
\hline To learn how to solve difficult problems* & $5.6(0.15) ; 6$ & $5.4(0.22) ; 5.5$ & $4.2(0.25) ; 5$ \\
\hline To gain an appreciation of scientific views of the world* & $5.1(0.14) ; 5$ & $5.1(0.23) ; 5$ & $3.9(0.24) ; 4$ \\
\hline To become empowered in everyday life* & $4.9(0.18) ; 5$ & $4.9(0.17) ; 5$ & $3.7(0.26) ; 4$ \\
\hline To learn how to communicate as a scientist* & $4.6(0.19) ; 5$ & $4.8(0.25) ; 5$ & $3.7(0.24) ; 4$ \\
\hline To understand how everybody can do science* & $5.6(0.17) ; 6$ & $5.5(0.21) ; 6$ & $4.6(0.24) ; 5$ \\
\hline $\begin{array}{l}\text { To learn how to perform scientific investigations } \\
\text { (i.e., scientific methodology) }\end{array}$ & $5.4(0.17) ; 6$ & $5.3(0.24) ; 5$ & $4.7(0.26) ; 5$ \\
\hline To learn how to participate in a functional group & $6.0(0.15) ; 6$ & $5.8(0.19) ; 6$ & $5.6(0.26) ; 6$ \\
\hline To become excited about science & $4.8(0.21) ; 5$ & $4.5(0.29) ; 4.5$ & $3.7(0.30) ; 4$ \\
\hline To have science "demystified" (i.e., for science to be accessible)* & $5.4(0.18) ; 6$ & $5.0(0.22) ; 5$ & $4.2(0.27) ; 5$ \\
\hline
\end{tabular}


did in section 2. However, we must be cautious about drawing conclusions from these data, since the scores are aggregate rather than paired by student.

Because of the small differences in the students' responses, only the data from the end of the semester are presented in Table IV. Frequency distributions for three items ("Learn science content knowledge," "Learn how to participate in a functional group," and "Become excited about science") are plotted in Figs. 1-3. Those three potential outcomes are especially interesting because, while the instructors and students both strongly valued the importance of learning science content knowledge, the students as a whole valued learning how to participate in groups significantly more $(p<0.05)$ than learning content knowledge, even though instructors did not see that as a primary function of PAT. In fact, one instructor suggested that any outcome related to working in groups would be due to coincidence rather than his intention.

On the other hand, instructors-especially the science education instructors-considered the opportunity for students to become excited about science in PAT to be a top priority, because teachers who are excited about science are more likely to teach it; however, as can be seen from Fig. 2, students were more neutral toward that possible outcome. In fact, eight of the 76 respondents rated that potential outcome " 1 " (very unimportant). Thus, looking at these three distributions provides detail into how students and instructors differ in terms of expected goals for PAT.

Students also reported how well they felt they personally achieved each of the 12 possible outcomes in PAT. Because there was no reason to assume that students in each section would perceive the same level of success in meeting these outcomes, responses to those items were analyzed by section (see Table IV). Overall, students reported that

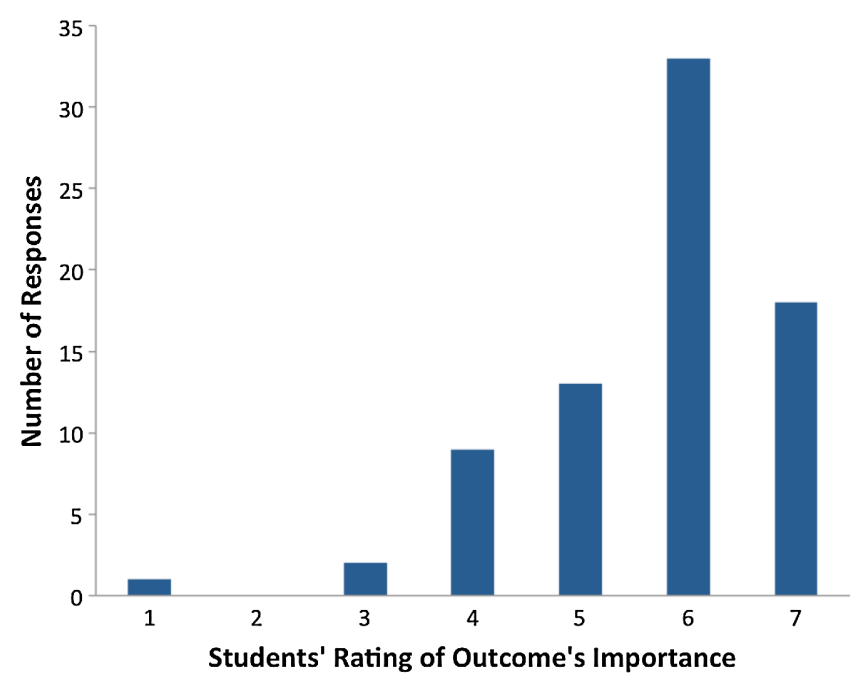

FIG. 1 (color online). Students' rating of how important it would be for them to learn physics content as a result of PAT; a rating of 7 means "very important (crucial)."

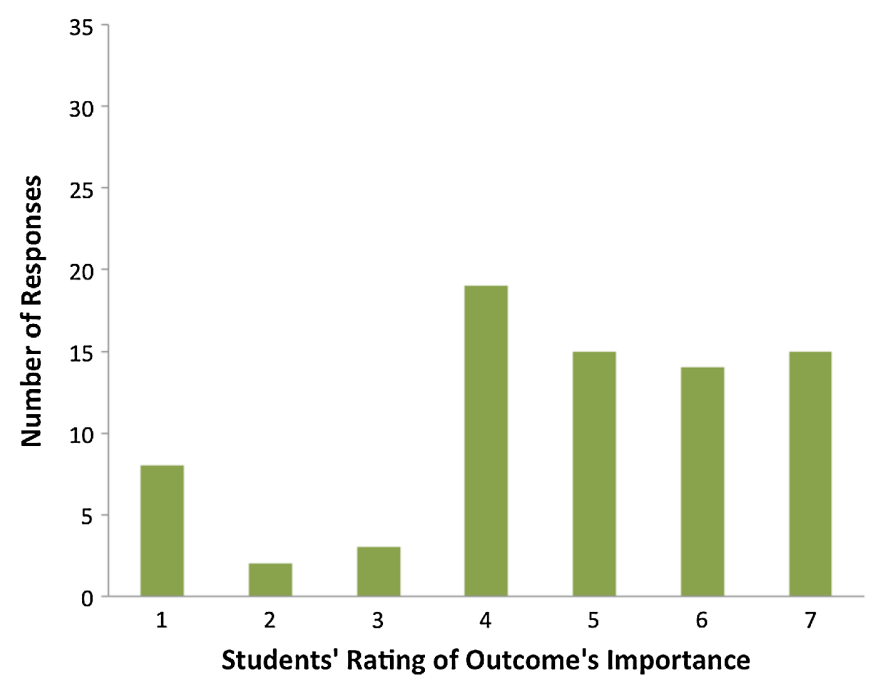

FIG. 2 (color online). Students' rating of how important it would be for them to get excited about science as a result of PAT; a rating of 7 means "very important (crucial)."

PAT was moderately successful in helping them meet those potential outcomes, although significant differences did emerge between the sections, with students in section 1 claiming more success than those in section 2 on a few items. Students in section 2 reported a greater degree of expectancy violation, although investigation of a possible connection between expectancy violation and how well students achieved their goals for the course is beyond the scope of this paper.

Students' reported success with respect to the outcomes listed above ("Learn science content knowledge," "Learn how to participate in a functional group," and "Become excited about science") were not significantly different

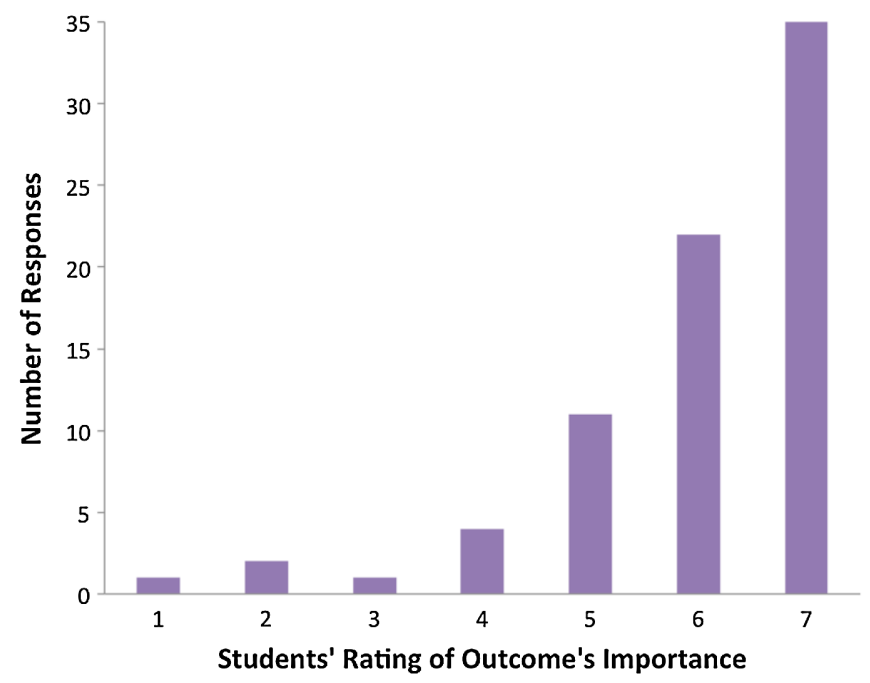

FIG. 3 (color online). Students' rating of how important it would be for them to learn how to participate in a functional group as a result of PAT; a rating of 7 means "very important (crucial)." 


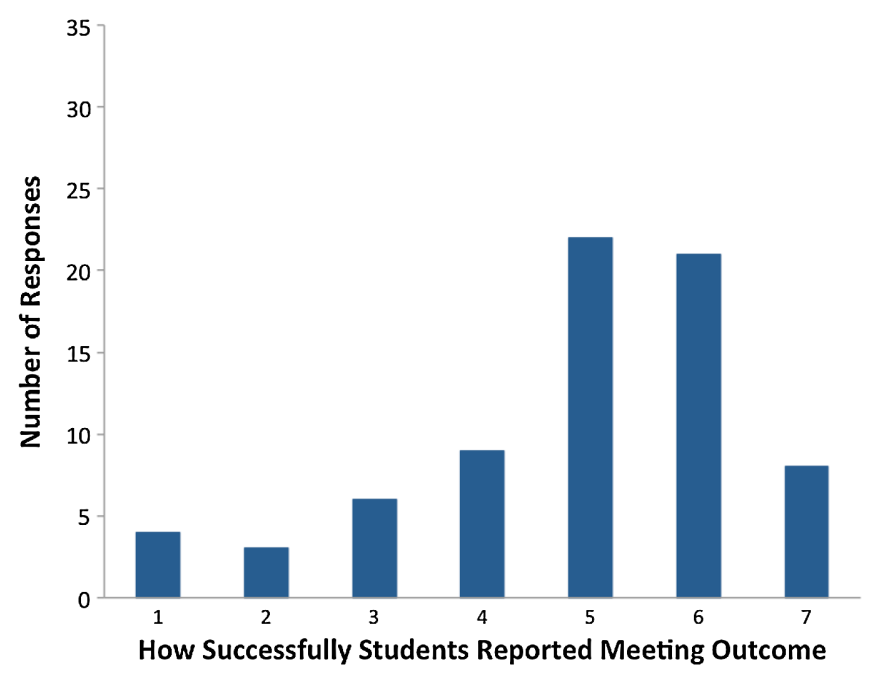

FIG. 4 (color online). Students' rating of how successful they were in learning physics content as a result of PAT; a rating of 7 means "very successful."

between the two sections and were combined for analysis. The class as a whole reported more success in learning how to participate in a functional group (Fig. 6) than with either learning physics content (Fig. $4 ; p<0.001$ ) or becoming excited about science (Fig. 5; $p<0.001$ ).

There was no item in the outcomes survey indicating the possible outcome of learning to teach science, but students frequently mentioned that goal in interviews and in the free-response section of the surveys. For example, one middle school major stated that, "Because it's for teachers, I expected something that would be more applicable to middle school students... I was hoping that this would definitely do something more useful in the classroom." She did find that the class supported that outcome, stating

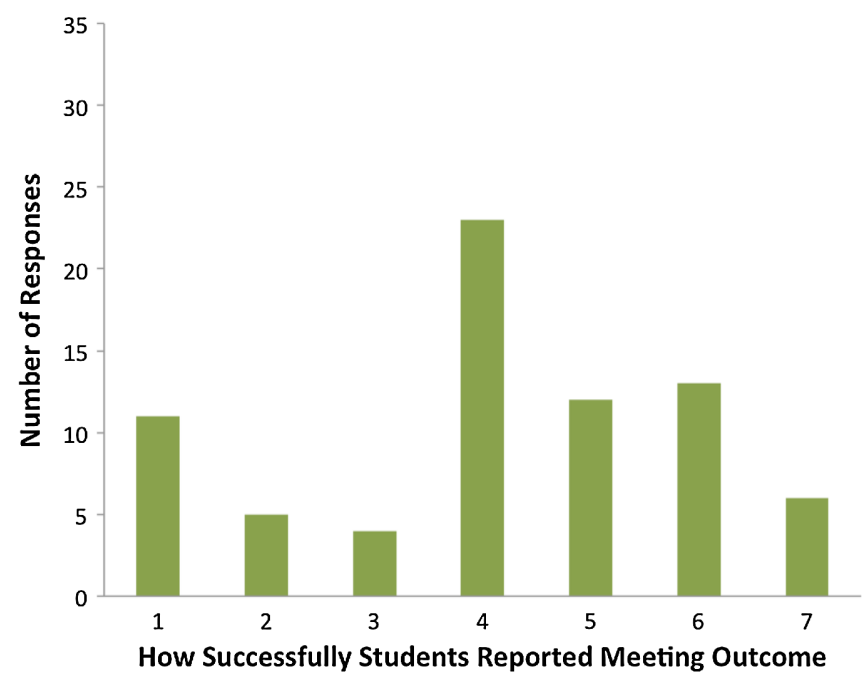

FIG. 5 (color online). Students' rating of how successful they were in getting excited about science as a result of PAT; a rating of 7 means "very successful."

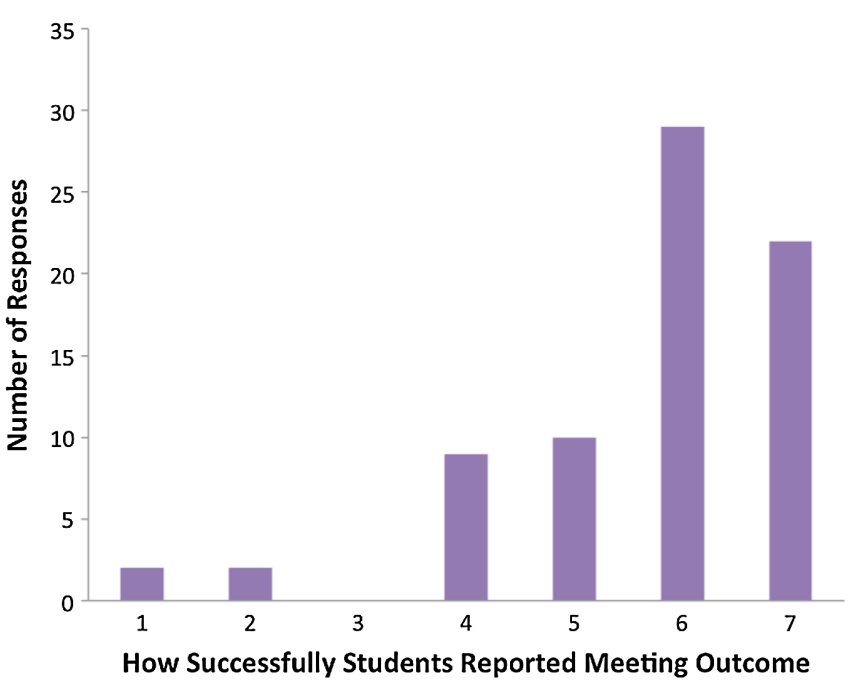

FIG. 6 (color online). Students' rating of how successful they were in learning how to participate in a functional group as a result of PAT; a rating of 7 means "very successful."

later that she did learn about how to teach, but indirectly: "I learned what I found more exciting and less exciting, and what was frustrating, what didn't work out necessarily for me, and you know a lot of the things that we did we could simplify them for middle school students."

Similarly, an elementary education major stated that she "expected more [learning on how to teach], just because it's an elementary education class. Most classes that are geared towards elementary, you know, you actually teach a lesson." Variations on those responses were a recurring theme: both elementary and middle school majors indicated that they had hoped to learn about teaching in PAT.

As a whole, the students reported more success in PAT on outcomes that they valued more, as can be seen from Table IV. A possible implication here is that if the students understand and value the same goals as the instructor, they will achieve more success in meeting those goals, which the instructor could interpret as an appropriate implementation of the course. However, further studies would be needed to determine the predictive nature of students' perceptions about valuable goals in the course in terms of what the students later accomplish in the course.

\section{DISCUSSION}

Outcomes that more directly related to students' future need to teach children were generally rated more highly than those related to their individual development and appreciation of science. Furthermore, students generally expected this course, as an education requirement, to provide teaching skills and resources that they could use in their own classrooms. In terms of the course's pedagogy, they expected a traditional science class with frequent lecture and whole-class discussion components, rather than a small-group, inquiry-based environment. Thus, 
students found themselves in a course that they did not expect, an experience likely to be uncomfortable. Orientation to the course only provided minor support, and students reported that they needed to "get into the groove" of the course before their frustration was alleviated.

\section{A. Role of PAT}

The instructors' envisioned role of PAT, that of a rigorous science content course that provided instruction via the same pedagogical style that the future teachers would expect to use, was not apparent to students. Students referenced PAT as an "education course," presumably because it was a requirement of the program, and while they seemed to expect certain features of the course that were appropriate, such as exposure to content, they also expected aspects of the course that were not explicitly intended, such as learning how to function in a group setting or having discussions about how to teach science.

Students' expectations about the role of PAT were probably not well formed, considering that during interviews students usually implied that PAT was just another item on a checklist: "I just wanted to be able to get through it," "I wanted to get a good grade," or "I just took it because I have to." Some students did indicate an expectation that PAT would help them become better science teachers. One student stated that she "wanted to learn a lot of stuff that I could use in my classroom. I wanted to be able to apply the knowledge to the classroom." Indeed, it became clear through interviews and observations that many of the students wanted to be able to apply what they learned in PAT directly; in other words, that they would learn science lessons they could turn around and use in the elementary or middle school.

When asked in interviews how this course could be made more directly applicable to their future careers, the overwhelming response from the participants was to somehow integrate an opportunity for teaching. Because PAT is required for education majors, students often indicated that it should include a component where they learn how to teach or practice teaching the material:

I would've liked to have maybe, and this sounds crazy, but I would've liked to maybe teach in it a little bit. To do, with one of our groups, to actually get up there and teach the class as if we were teaching a class of our own. Because I think that's always helpful.

By working in groups, some students felt they got that opportunity to teach, but it was teaching for the sake of learning rather than teaching to rehearse behavior in their classrooms:

I think working with other people, and learning from them, instead of just having my own perspective, that helped me a lot. And being able to teach others, because when somebody else wouldn't get it and I would, explaining it to them helped me to remember it and understand it more.

When the students did not receive an opportunity to practice teaching, some of them became confused about PAT being a required course, leading to ambivalence:

....PAT] didn't seem entirely disconnected, but it wasn't like a-I didn't feel like it was a teacher's class... Like, sometimes when I wasn't understanding I would still feel like the student, and so I didn't have to help others... it might be more applicable if... someone had to teach either the class or whatever, to be able to practice that and learn it.

A middle school education major added that although the course was well suited for her prospective grade level (and her science specialization), it would not be appropriate for elementary majors:

I don't feel like this class is beneficial for elementary educators, because the elementary education curriculum is so different, you don't really have time to use what you know... I feel like the stuff we do is so advanced that I struggle with it as a college studenthow are you going to teach that to a second grader? You know, like you would have to completely change a lot of things we're doing, and I don't know if that's possible to incorporate some kind of difference in what you are learning into the class to maybe-not like dumb it down, but like, you know what I mean?

The role of PAT was unclear to the students, and it was therefore not surprising when their expectations for the course were different from their experiences.

\section{B. Pedagogy in PAT}

With little understanding about how PAT was intended to fit into their professional development, students' initial expectations were likely shaped by characteristics of courses that they had previously taken: lecture, detailed instructions, and class-wide discussions were highly expected (see Tables I and II). In an interview early in the semester, one student indicated that she "thought it was going to be mostly lecture and then occasionally lab." However, students also expected to work together, investigate how things work, and solve problems. One reason for such expectations is that PAT had been around for many years, and some students indicated that they had friends who had previously taken the course: "Well, all of my friends took it last semester, so I already knew what was going to happen. We'd come in and do stuff and leave when we were done." In a postinterview, a different student who 
had friends who previously took this course summarized this dichotomy:

I guess I knew it was going to be hands-on. I definitely thought there would be more lecture. I don't know, I just thought that since there was so much lab time, I felt like they needed-I felt like there [were] going to be a lot more lectures. I understand that we did the few minutes in the beginning, but I still expected to be about half lecture and half work.

In fact, students tended to appreciate the hands-on nature of the course; one student added that "the hands-on stuff really did help. Because, I mean, I've always known that hands-on work is effective, but this course helped me to understand it a little bit better."

Students both expected and experienced many hands-on activities in PAT, and they valued those experiences. On the other hand, they continued to expect lecture. This is understandable, as many of the students had never experienced a course without a substantial lecture component before. It also set them up for expectancy violations, since they reported receiving few lectures and class-wide discussions, perceptions that were confirmed through classroom observation. Students frequently reported wanting more lecture, in terms of both content delivery and more guidance for doing their in-class activities.

Because of the sharp difference between students' expectations and their experiences for certain activities but not others, students found themselves in a somewhat different course than they had imagined, a potentially jarring situation that resulted in mixed affect. Some students appreciated the value given to exploration: "one good thing this class did was [that it was] very hands-on [and] let me work with different things," while others indicated that lecture would have helped them understand what was happening in the course better:

I do wish there had been more lecture in [PAT]. Because at times we, I remember thinking like, we have no idea what we are doing. Like, you know, for example today's lab, we were just kind of thrown into it, like 'what?' Like we had no idea what to do.

There was a rich interplay between the students' expectations for the role of the course and their expectations for the pedagogy. For example, students reported fewer opportunities to make presentations of their work than they expected; if a goal of the course was to provide teaching experience, one might expect students to make such presentations, at least occasionally. Also, because PAT was required before much exposure to education courses or to K-8 observations, students likely had little idea how they would be expected to teach in the classroom. Thus, when they found themselves learning through methods that were more common in elementary school than the university, students were uncomfortable and had to learn to adapt.

\section{Adapting to PAT}

Interviews at the conclusion of the semester revealed that, while initially large for some activities, the gap between expectations and experiences was subject to change. As the course progressed, some students acclimated to the environment. One student referred to this process as "getting into the groove" of the course: "I had different expectations going in but then once I got in and kind of got into the groove of it, [they] didn't change I guess." Getting into the groove happened more quickly for some students than others. One student said that, "There were no surprises as far as, you know, [the instructor] did exactly what he said he was going to do. I was surprised that I liked it so much." On the other hand, a different student said that it "took a little while because I wasn't, I was like, oh this is the routine we are going to get into. It took me a while to adapt to that." As that adjustment was happening she was uncomfortable:

It was a little unnerving. Because I wanted to get [the answers] right, but you're not, you don't know everything, that's why you are in the class. And so that'syeah, I don't like it when people look at my work and assess it with me face-to-face. I don't like being critiqued. So that was hard.

That student eventually adapted, resulting in a shift in her mindset:

I got out of that being afraid of being wrong thing, because it's not like they smack you on the hand or said, 'bad,' it was just, you know, you learned from it and you changed. And I think that is where a lot of my learning happened, is when I did get things wrong and had to think, 'no this isn't how it's done, this is how it's done.'

Because of her experience, she suggested the following advice to future students:

Try to adapt to a different way of learning, get used to getting a little bit outside of your comfort zone when it comes to working with people, and getting your work critiqued by teachers. Because that's, I mean that's not something you get in a normal class.

As we see with this student, adjustment to the course was difficult, and frustration was tangible in observations and experiences with her during the transition to acceptance. Some students make this transition quickly, while others may never fully make it. The results from the PEVA indicate that for the class as a whole, very little of that 
transition was made during the first class meeting; instances of expectancy violation remained even after the instructor, verbally and in the syllabus, explicitly told the students what they should expect from the class. Therefore, students were still expecting something other than they experienced from the class and had to make the adjustment on their own.

In conclusion, students exhibited dissatisfaction with PAT when the class was not meeting their expectations, both in terms of the ways they would be learning in the class and in terms of the role that PAT was playing in their professional development. As students adjusted to the course, some of them began to get into the groove of the course and feel more comfortable. However, this adjustment largely did not happen immediately. Possibly because the orientation to the class was largely ineffective, students continued to be confused and frustrated about certain aspects of the course, including its purpose, lack of teaching preparation, and lack of time devoted to lecture and whole-class discussions.

\section{Implications}

Multiple implications follow from this study, both for the continued development of PAT and for course design elsewhere.

\section{Continued development of PAT}

This physics content course for elementary education majors has a very specific purpose in the eyes of the instructors, but that role seems not to be fully understood by the students. Incomplete communication about the role of PAT, especially as the students are being oriented to the course, is a likely culprit for confusion and dissatisfaction with the course, since students do not initially understand why they are required to take PAT. Effort should be made, before students ever begin the course, to make the case for its relevance in their preparation to become teachers.

The expectancy violation feedback produced by this study is directly useful to instructors in PAT. For example, consider class discussions, which students claimed to have experienced less often than they expected. One simple remedy for more closely aligning students' experiences with their expectations is by holding more class discussions to discuss recent in-class investigations and to share students' observations. Doing so would allow instructors to meet some expectations of the students without dismissing the importance of hands-on activities. To further meet students' expectations (in this case, of presenting work to the class), students could be given the opportunity to lead such discussions themselves.

Instead of lectures or class discussions, instructors in PAT held conversations with individuals and groups during checkpoints. While such discussions served a lecturelike role by organizing and summarizing the work that was just done, they were apparently not seen as an adequate substitute for lecture from the student's perspective. Explicit, ongoing discussion about the process of inquiry-especially why students' learning depends on using observed phenomena as the authority rather than the instructor-is imperative to develop students' metacognitive skills. Indeed, some studies have found that explicitly teaching epistemology does affect attitudes and behavior $[23,24]$. Furthermore, students need to be able to express their frustration with the process in a safe and productive way, and instructors should acknowledge that frustration without compromising their goals.

Another expectation of students was that they would learn how to teach the material that they were learning, or that at least they would have an opportunity to practice teaching. Instructors of PAT should continue to communicate PAT's role as a physics content course that models inquiry, rather than as a class where students will practice teaching or develop content that they will be able to use with their future students. Alternatively, PAT instructors could work with science methods instructors to provide opportunities within the class for students to practice teaching the content they are learning.

It is also important for instructors to realize that students in PAT appreciated the hands-on aspect of the course. Students valued the opportunity to construct their own knowledge, and they perceived it as valuable experience to have gained. This information helps put their other criticisms into perspective: PAT is largely successful at accomplishing its mission, but certain tweaks may allow students to view it more positively.

\section{Course development elsewhere}

If instructors expect to cultivate satisfied students who appreciate a given course's methods and purpose, they should ensure that they meet students' expectations and goals. Thus, instructors need to both thoroughly communicate the process and purpose of the course as well as understand students' initial expectations regarding the pedagogy, especially if that pedagogy is not traditional.

Orientation to the course should consist of more than reading the syllabus aloud on the first day of class, especially when the course is as unique as PAT. Some examples of ways to orient the course include engaging in a typical activity for the course, explicitly linking such activities with the underlying philosophical reasons for teaching that way (especially in a course designed for teachers), and soliciting and discussing rumors students have heard about the course. This latter option provides students an opportunity to negotiate what will happen in the course, as well as for them to voice their fears in a safe atmosphere. Orientation should be ongoing, and a consistent message should be communicated throughout the semester.

Communicating expectations to students means more than delivering expectations to students verbally or via the syllabus. For courses like PAT, it means approaching 
each class meeting-including the first one-with explicit expectations for student behavior. A substantial portion of their grade should come from expected behavior (such as asking questions, investigating physical phenomena, and actively sense making), and such behavior should be routinely praised. At the same time, instructors should be patient, especially in a course that could be substantially different from others the student has experienced. Within PAT, that means fostering a safe environment and regularly encouraging students to contribute their thoughts and ideas as they strive to construct an understanding of physical concepts. Sometimes that means something as simple as having students make and display name tents or giving gold stars to students who offer exceptionally well thoughtout, risky, or clever ideas.

\section{E. Limitations}

There are multiple limitations that are inherent in this study. First, by being an active part of the classroom, my observations naturally affected the class. I reacted to students' frustration by actively seeking resolution, for example, by meeting with students individually to provide study skills, rather than simply recording such occurrences. However, being an instructor also provided me with powerful observations about what was happening "on ground level" in the classroom and therefore supported insights about how to alleviate frustration and improve the course.

Responses were collected from the surveys on paper with one exception: the first time the survey was given to section 1, it was online to prevent lost time in class. However, the response rate was poor, which might have introduced a selection bias into those results. To work around that bias, sections were combined when possible (since it was assumed that the students randomly selected into one section or the other, a reasonable assumption given that there were few significant differences in initial responses between the sections). Additionally, all students were given the opportunity to participate in an interview, but only a few responded, meaning that there could have been a bias in responses received there. Triangulation with the surveys and observations helped minimize this potential effect.

Finally, one should be cautious generalizing from this small data set: both sections were during the same semester at the same university. It is likely that the culture at a different university, or during a different semester, would be substantially different. Therefore, this study should be interpreted as a case study of how a largely successful inquiry-based course continues to wrestle with issues of student affect. As such it lends insights regarding overarching issues, such as the interplay between students' expectations and experiences in the classroom and the importance of understanding students' perspectives in a class, especially in one substantially unlike any other course the students have experienced.

\section{F. Conclusions}

When students entered PAT, they held a range of expectations regarding both the pedagogy they would experience and the role of the course in their education. As a whole, students expected both lecture and hands-on activities in a fairly standard lab-lecture design, even though many of the students had friends who had previously taken PAT. Students generally did not have a developed sense of the purpose of the course, assuming both that it was an item to check off their list and that it would somehow prepare them to teach science. Students valued somewhat different outcomes than did instructors, indicating a disconnect that likely led to misaligned expectations regarding the role of the course.

Some of students' initial expectations about the course, such as the frequency with which they would interact with each other and the instructors and the fact that the course would contain much hands-on investigation, were similar to their actual experiences. In those instances where expectancy violation did not occur, students were generally very positive. However, students also expected far more frequent lecture, whole-class discussions, and opportunities to present and practice teaching than they received, indicating an expectancy violation that seemingly led to confusion and frustration within the course. Orientation to the course, which consisted mostly of the instructor reviewing the syllabus and process of the course, did not shift those expectations or alleviate those areas of negative affect. Some frustration was alleviated for students who acclimated to the course, a process that was immediate for some and quite slow for others. A suggestion for improving student affect in courses like PAT would be to dedicate class time and instructor effort to more thoroughly orienting students to the course by providing explicit instruction on epistemology, reinforcing the purpose of the course, and explaining the reasons behind pedagogical choices, both at the beginning of the course and throughout the term.

A major effort of STEM reform is to improve the preparation of middle and elementary school teachers, so that they will teach more high quality science. Teachers who are intimidated or frustrated by physics are likely to avoid physical science topics in their classrooms. As such, physics content courses must not only improve content knowledge, but they must avoid generating negative affect with respect to physics. This study suggests that such negative affect arises within the classroom when students are unsure of the role of the course within their professional development (for example, treating it as an education course rather than a science course) and when their expectations about how they will learn are violated (for example, when there are fewer lectures or opportunities to present their work to the class than they expect). When instructors are cognizant of such violations, they can produce more effective orientations to reduce that negative affect and 
thus be more successful in motivating future teachers to teach science.

\section{ACKNOWLEDGMENTS}

I would like to express my appreciation and gratitude for the faculty at the University of Kentucky for their willingness to participate in this study, as well as to the creators of PAT, for many discussions about its genesis. I am also appreciative of discussions with other faculty nationwide who teach courses like PAT and helped in the creation of the survey items. This manuscript was greatly enhanced due to helpful comments from anonymous reviewers, for whom I am thankful. This work was funded by the College of Arts and Sciences, the College of Education, and the College of Communication and Information at the University of Kentucky.

\section{APPENDIX A: CLIFF'S DELTA}

Cliff's delta $(\delta)$ compares each entry in one data set to each entry in another data set, and it produces a value between -1 and +1 . A value of -1 means that each entry in the second set was lower than each entry in the first set [42]. When the samples are both fairly large and representative of the population, we assume that differences in interpretation on Likert scales (for example, one participant's " 4 " being equivalent to another participant's " 5 ") will wash out in the ranked comparison of the arrays, while true differences (for example, all of the participants selecting $N$ on the first survey and $N-1$ on the second) will persist. Therefore, while $\delta$ does not provide paired information, it does provide detailed information on how responses compare to different prompts or to the same prompt over time, even when the movement is small. By providing a quantification of the difference between the samples, we can determine a range of confidence that the difference we see is real as opposed to statistical fluctuation.

One alternative option for analyzing the data would be to "bin" the data, for example, combining responses of "somewhat frequently, frequently, and very frequently," and comparing the number of those responses to different prompts. While this method for analyzing Likert-style survey data is valid in certain situations, it is most appropriate when comparing students' responses to a binary choice. For example, in the CLASS [22], student responses were compared to those of experts and used to track whether student responses became more or less expertlike. However, for the data from the PEVA and the student outcomes survey in this study, there is no expectation of a binary response or of the value "4" ("sometimes" or "neutral") having any unique value. Rather, subtle movements of the distribution of responses are important as we seek to understand how students' expectations change and compare with their experiences. Therefore, it is important to track and consistently quantify the size of the difference between distributions. The role of $\delta$ is clarified in the following example.

The first pedagogical activity considered on the PEVA is "lecture." On the same survey, students provided two responses about their expectations: how frequently they had expected lecture when they enrolled, and then how frequently they expected lecture after the orientation to the class. There were 63 responses to the first question $(m=4.97$, median $=5)$ and 62 responses to the second $(m=4.02$, median $=4)$, resulting in 61 paired responses. Of those 61 students, 30 responded that they expected lecture less frequently than before orientation, 9 expected it more, and 22 still expected it the same. Collapsing the data shows a shift from 38/63 expecting lecture frequently when enrolling to $28 / 62$ expecting lecture frequently after orientation. $\delta$ for this situation was -0.28 , with a $95 \%$ confidence interval from -0.08 to -0.46 . Any method of analyzing that data would yield the same conclusion: students expected less lecture after they were oriented to the class. However, $\delta$ was fairly small, and caution should be taken to avoid overstating the effect that binning the data might suggest.

The third item on the PEVA was "solving problems in a group." Again, there are results for expectations before $(N=64, m=6.06$, median $=6)$ and after orientation $(N=62, \quad m=6.50, \quad$ median $=7)$, with 61 paired responses. Of those 61 students, 7 expected it less frequently after orientation, 25 more, and 30 expected it the same amount. Collapsing the data shows that 59/64 participants expected to solve problems in a group frequently when enrolling, and 60/62 expected to solve problems in a group frequently after orientation. $\delta$ for this situation was 0.28 , with a $95 \%$ confidence interval from 0.10 to 0.45 . Here, collapsing the data loses all of the subtlety of the shifts in responses because that shift did not occur around the "sometimes" point ("4"). Nonetheless, as hinted at by the means and medians, there was clearly a one-sided shift in responses; $40 \%$ of the students expected to solve problems in a group more frequently than before. $\delta$ manages to capture that information successfully even though the analysis was done with aggregate data rather than paired data.

Thus, $\delta$ successfully indicates some amount of individual student differences, even though it is an aggregate analysis method rather than an ability to look at paired data. Additionally, it does not overvalue shifts near the neutral point, which is appropriate because there is nothing special about that point in this study. The above analysis provides a check on the reliability and usefulness of $\delta$ in studies such as this, where it is important to understand not only whether a shift occurred, but also its relative size. In that way, $\delta$ provides a sort of "effect size" measure that can be used to compare different distributions. 


\section{APPENDIX B: EXPECTANCY VIOLATION SURVEY ITEMS}

Fifteen items were included in the survey, prefaced with the anchor, "Indicate how often you (expected to experience or experienced) the following during this semester's PAT, using the following scale" (ranging from 1, very infrequently, to 7 , very frequently):

(1) Lecture.

(2) Solving problems on my own during class.

(3) Solving problems in a group during class.

(4) Investigating how things work during class.

(5) Class-wide discussions of scientific concepts.

(6) Class-wide discussions of ways to teach science.

(7) Class-wide discussions of the nature of science.

(8) Answering questions from my instructors or TAs during class time.

(9) Answering questions from my classmates during class time.

(10) Asking questions about science of my instructors or TAs during class time.

(11) Asking questions about science of my classmates during class time.

(12) Presenting and explaining my work to the class.

(13) Writing in my own journal detailing class events.

(14) Building my own understanding of concepts.

(15) Receiving detailed instructions for doing scientific investigations.

\section{APPENDIX C: POSSIBLE OUTCOMES SURVEY ITEMS}

Twelve items were included in this survey. Students indicated how important they believed these potential goals were on a 7-point Likert scale, with 1 for items that were "very unimportant (trivial)" and 7 for items that were "very important (crucial)":

(1) To learn science content knowledge (e.g., to learn about electricity).

(2) To learn how to argue scientifically.

(3) To appreciate the benefits of a hands-on, interactive approach to teaching science.

(4) To learn how to solve difficult problems.

(5) To gain an appreciation of scientific views of the world.

(6) To become empowered in everyday life.

(7) To learn how to communicate as a scientist.

(8) To understand how everybody can do science.

(9) To learn how to perform scientific investigations (i.e., scientific methodology).

(10) To learn how to participate in a functional group.

(11) To become excited about science.

(12) To have science "demystified" (i.e., for science to be accessible).
[1] National Research Council, Rising Above the Gathering Storm: Energizing and Employing America for a Brighter Economic Future (The National Academies Press, Washington, DC, 2007).

[2] National Research Council, National Science Education Standards (National Academy Press, Washington, DC, 1996).

[3] For example, see Kentucky Senate Bill 1, http:// www.lrc.ky.gov/record/09RS/SB1.htm.

[4] Council on Postsecondary Education STEM Task Force, Kentucky's STEM Imperative: Competing in the Global Economy, 2007.

[5] National Task Force on Teacher Education in Physics, National Task Force on Teacher Education in Physics: Report Synopsis, 2010.

[6] National Research Council, How Students Learn: History, Mathematics, and Science in the Classroom (National Academy Press, Washington, DC, 2005).

[7] When released, the standards will be available at http:// www.nextgenscience.org.

[8] Lillian C McDermott, Physics by Inquiry (John Wiley and Sons, New York, 1996).

[9] Fred Goldberg, Steve Robinson, and Valerie Otero, Physics and Everyday Thinking (It's About Time, Armonk, NY, 2008).
[10] Priscilla W. Laws, Calculus-based physics without lectures, Phys. Today 44, No. 12, 24 (1991).

[11] Information about the Appalachian Math and Science Partnership can be found at http://appalachian .mspnet.org/.

[12] Kathy Cabe Trundle, Ronald K. Atwood, and John E. Christopher, A longitudinal study of conceptual change: Preservice elementary teachers' conceptions of moon phases, J. Res. Sci. Teach. 44, 303 (2007).

[13] Ronald K. Atwood, John E. Christopher, and Rebecca McNall, Elementary teachers' understanding of standards-based light concepts before and after instruction, in Proceedings of the National Association for Research in Science Teaching, Dallas, TX, 2005 [http://appalachian.mspnet.org/index.cfm/14108].

[14] Charles Henderson, Melissa Dancy, and Magdalena Niewiadomska-Bugaj, Use of research-based instructional strategies in introductory physics: Where do faculty leave the innovation-decision process? Phys. Rev. ST Phys. Educ. Res. 8, 020104 (2012).

[15] J.W. Belcher, Improving student understanding with TEAL, MIT Faculty Newsletter, Vol. XVI, No. 2 (2003) [http://web.mit.edu/jbelcher/www/TEALref/ fnlEditedLinks.pdf]. 
[16] R. J. Beichner et al., The student-centered activities for large enrollment undergraduate programs (SCALE-UP) project, in Research-based Reform of University Physics, Reviews in PER Vol. 1, edited by E. F. Redish and P. J. Cooney (American Association of Physics Teachers, College Park, MD, 2007).

[17] David Hammer, Epistemological beliefs in introductory physics, Cognit. Instr. 12, 151 (1994).

[18] A. Elby, Another reason that physics students learn by rote, Am. J. Phys. 67, S52 (1999).

[19] E. F. Redish and D. Hammer, Reinventing college physics for biologists: Explicating an epistemological curriculum, Am. J. Phys. 77, 629 (2009).

[20] Edward F. Redish, Jeffery M. Saul, and Richard N. Steinberg, Student expectations in introductory physics, Am. J. Phys. 66, 212 (1998).

[21] A. Elby, J. Fredriksen, C. Schwartz, and B. White, Epistemological beliefs assessment for physical science [http://www2.physics.umd.edu/ elby/EBAPS/home.htm]

[22] W. K. Adams, K. K. Perkins, N. S. Podolefsky, M. Dubson, N. D. Finkelstein, and C. E. Wieman, New instrument for measuring student beliefs about physics and learning physics: The Colorado Learning Attitudes about Science Survey, Phys. Rev. ST Phys. Educ. Res. 2, 010101 (2006).

[23] K. Otero and K. E. Gray, Attitudinal gains across multiple universities using the Physics and Everyday Thinking curriculum, Phys. Rev. ST Phys. Educ. Res. 4, 020104 (2008).

[24] E. Brewe, L. Kramer, and G. O'Brien, Modeling instruction: Positive attitudinal shifts in introductory physics measured with CLASS, Phys. Rev. ST Phys. Educ. Res. 5, 013102 (2009).

[25] Beth A. Lindsey, Leonardo Hsu, Homeyra Sadaghiani, Jack W. Taylor, and Karen Cummings, Positive attitudinal shifts with the Physics by Inquiry curriculum across multiple implementations, Phys. Rev. ST Phys. Educ. Res. 8, 010102 (2012).

[26] N. D. Finkelstein and S. J. Pollock, Replicating and understanding successful innovations: Implementing tutorials in introductory physics, Phys. Rev. ST Phys. Educ. Res. 1, 010101 (2005).

[27] J. K. Burgoon, A communication model of personal space violations: Explication and an initial test, Hum. Commun. Res. 4, 129 (1978).

[28] J. K. Burgoon, Intercultural Communication Theory (Sage, Thousand Oaks, CA, 1995), pp. 194-214.
[29] J. K. Burgoon and J. L. Hale, Nonverbal expectancy violations: Model elaboration and application to immediacy behaviors, Commun. Monogr. 55, 58 (1988).

[30] D. Hammer, A. Elby, R. Scherr, and E. F. Redish, Transfer of Learning from a Modern Multidisciplinary Perspective (Information Age Publishing, Greenwich, CT, 2005), pp. 89-120.

[31] A. B. Frymier and B. Weser, The role of student predispositions on student expectations for instructor communication behavior, Commun. Educ. 50, 314 (2001).

[32] J.B. Dusek, Teacher Expectancies (Erlbaum, Hillsdale, NJ, 1985).

[33] M. B. McPherson, P. Kearney, and T. Plax, The dark side of instruction: Teacher anger as classroom norm violations, J. Appl. Commun. Res. 31, 76 (2003).

[34] R. L. Oliver, A cognitive model of the antecedents and consequences of satisfaction decisions, J. Market. Res. 17, 460 (1980).

[35] M. J. Bitner and A. R. Hubbert, Service Quality: New Directions in Theory and Practice (Sage, Thousand Oaks, CA, 1994), pp. 72-94.

[36] Sara L. Appleton-Knapp and Kathleen A. Krentler, Measuring student expectations and their effects on satisfaction: The importance of managing student expectations, J. Market. Educ. 28, 254 (2006).

[37] J. Charlene Davis and Scott T. Swanson, Navigating satisfactory and dissatisfactory classroom incidents, J. Educ. Bus. 76, 245 (2001).

[38] Jon D. H. Gaffney, Amy L. Housley Gaffney, and Robert J. Beichner, Do they see it coming? Using expectancy violation to gauge the success of pedagogical reforms, Phys. Rev. ST Phys. Educ. Res. 6, 010102 (2010).

[39] Joseph P. Straley, University of Kentucky: Online Physics for Teachers, 2004, http://www.pa.uky.edu/sciworks/ intro.htm.

[40] In the fall of 2010, all lead and assistant instructors of PAT were male.

[41] M. Hollander and D. A. Wolfe, Nonparametric Statistical Methods (Wiley-Interscience, New York, 1999), 2nd ed.

[42] J. Romano, J. D. Kromrey, J. Coraggio, and J. Skowronek, Appropriate statistics for ordinal level data: Should we really be using t-test and Cohen's d for evaluating group differences on the NSSE and other surveys?, in Proceedings of the Annual Meeting of the Florida Association of Institutional Research, Cocoa Beach, FL, 2006, http://www.florida-air.org/romano06.pdf. 